\title{
ORIGEN Y EVOLUCIÓN DE LA COOPERACIÓN INTERNACIONAL PARA EL DESARROLLO*
}

\author{
Origin and Evolution of International Cooperation for Development
}

Origem e evolução da cooperação internacional para o desenvolvimento

RECIBIDO: 16 DE SEPTIEMBRE DE 2014

Lisbeth Katherine Duarte Herrera

(Colombia) Magíster en Ciencias Sociales

Institución Universitaria Esumer

lisbeth.duarte@esumer.edu.co
EVALUADO:21 DE OCTUBRE DE 2014

ACEPTADO:28 DE OCTUBRE DE 2014

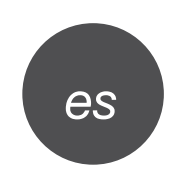

RESUMEN

Se presenta como mito fundacional de la cooperación internacional para el desarrollo los años inmediatamente posteriores a la Segunda Guerra Mundial con sucesos claros, como los planes de reconstrucción de Europa, el surgimiento del sistema de las Naciones Unidas y el proceso de descolonización. En sus orígenes, la cooperación internacional para el desarrollo era concebida casi exclusivamente como transferencia directa de recursos monetarios hacia un receptor para mejorar sus indicadores de desarrollo. Esta concepción de la cooperación internacional para el desarrollo atravesó una crisis o fatiga, a causa de los pobres resultados presentados durante más de tres décadas. Actualmente, la cooperación es repensada basada en una visión de desarrollo humano, que supera la visón exclusivamente economicista y vertical de las décadas anteriores. Superado estos problemas, la cooperación internacional para el desarrollo en la actualidad es dinámica y ajustable a las necesidades cambiantes del entorno internacional. Por otra parte, a pesar de sus altibajos, la cooperación internacional para el desarrollo se constituye como un elemento de suma importancia en el actual sistema internacional e incide de forma directa en la forma como se relacionan los diferentes actores de dicho sistema, actores tanto de naturaleza estatal como no estatal.

PALABRAS CLAVE: cooperación, desarrollo, relaciones internacionales, globalización, sociedad civil.

Carlos Hernán González Parias (Colombia) Institución Universitaria Esumer carlos.gonzalez88@esumer.edu.co

en

ABSTRACT

The years that followed World War II are considered the base for international cooperation with clear events such as the plans to rebuild Europe, the appearance of the United Nations, and the decolonization process. At the beginning, the international cooperation for development was conceived almost exclusively as the direct transfer of monetary resources to a recipient in order to improve its development indicators. This concept had a crisis or fatigue due to the poor results presented for over three decades. Nowadays, cooperation is reevaluated based on a vision of human development that goes beyond the merely economistic and vertical vision of the previous decades. Once these problems were overcome, the international cooperation for development became dynamic and adjustable to the changing needs of the international environment. Nevertheless, in spite of its ups and downs, it is a key element for the current international system and has a direct impact on the way the different actors (of state and non-state level) of this system interact.

KEYWORDS: cooperation, development, international relations, globalization, civil society.

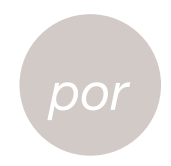

RESUMO

Apresenta-se como mito fundacional da cooperação internacional para o desenvolvimento os anos imediatamente posteriores à Segunda Guerra Mundial com sucessos claros, como os planos de reconstrução da Europa, o surgimento do sistema das Nações Unidas e o processo de descolonização. Nas suas origens, a cooperação internacional para o desenvolvimento era concebida quase exclusivamente como transferência direta de recursos monetários para um receptor para melhorar os seus indicadores de desenvolvimento. Esta conceição da cooperação internacional para o desenvolvimento atravessou uma crise ou fadiga, a causa dos pobres resultados apresentados durante mais de três décadas. Atualmente, a cooperação é repensada baseada em uma visão de desenvolvimento humano, que supera a visão exclusivamente economicista e vertical das décadas anteriores. Superados estes problemas, a cooperação internacional para o desenvolvimento na atualidade é dinâmica e ajustável às necessidades cambiantes do entorno internacional. Por outra parte, a pesar de seus altibaixos, a cooperação internacional para o desenvolvimento se constitui como um elemento de suma importância no atual sistema internacional e incide de forma direta na forma como se relacionam os diferentes atores de dito sistema, atores tanto de natureza estatal quanto não estatal.

PALAVRAS CHAVE: cooperação, desenvolvimento, relações internacionais, globalização, sociedade civil.

PARA CITAR ESTE ARTÍCULO/TO CITE THIS ARTILLE/PARA CITAR ESTE ARTIGO:

Duarte Herrera, L. K. y González Parias, C. H. (2014). Origen y evolución de la cooperación internacional para el desarrollo. Panorama, 8(15), 117-131.

* Este artículo es el primer resultado del proyecto de investigación Cooperación internacional, de la línea de investigación en Negocios y relaciones internacionales del grupo de investigación de la Facultad de Estudios Internacionales de la Institución Universitaria Esumer (Medellín, Colombia). 


\section{INTRODUCCIÓN}

En el sistema internacional actual, es indudable la enorme importancia que ha tomado la cooperación internacional para el desarrollo, hasta tal punto que con el paso de las décadas se ha logrado conformar un sistema y una compleja red de actores, instituciones, organismos y mecanismos orientados a este objetivo. Tal importancia, en buena medida, se sustenta gracias a la diversificación de la agenda internacional que actualmente va mucho más allá de temas económicos y de seguridad.

En este sentido, este artículo se erige como una contribución a un tema de suma pertinencia, como lo es la cooperación internacional para el desarrollo. Tal contribución se centra en realizar una reconstrucción de los orígenes, la evolución y los puntos de inflexión que ha surtido la cooperación internacional para el desarrollo.

Para tal objetivo, el método empleado es de tipo deductivo explicativo, donde, a partir de cuestiones generales y contextos históricos particulares, se reconstruye cada una de las etapas reconocidas y recorridas por la cooperación internacional para el desarrollo, para explicar su origen y evolución histórica. En este orden de ideas, la metodología empleada ha sido de revisión bibliográfica de fuentes especializadas en la temática planteada.

El presente artículo consta de la siguiente estructura: en una primera parte, se presenta una caracterización de lo que actualmente se entiende por cooperación internacional para el desarrollo, después de las transformaciones experimentadas durante la década de 1980, incluso sus tipos y fuentes. En una segunda parte, se recrea el contexto y los sucesos que dieron origen a la cooperación internacional para el desarrollo en el sistema internacional, como 1) la reconstrucción de Europa después de la Segunda Guerra Mundial, b) los procesos de descolonización africana, 3) las problemáticas derivadas de la globalización y 4) la crisis de la cooperación internacional.

\section{CONCEPTO DE COOPERACIÓN INTERNACIONAL PARA EL DESARROLLO}

Como gran parte de los conceptos desarrollados dentro de las ciencias sociales, el concepto de cooperación internacional para el desarrollo no tiene un criterio de unificación para definirlo. Este no posee una definición única que sea válida para todo tiempo y lugar. Como concepto, ha experimentado siempre cambios, en función del pensamiento, las políticas y los valores presentes en las relaciones internacionales.

La definición de la cooperación ha ido evolucionando y obteniendo nuevas connotaciones a la largo de su corta historia. Sin embargo, pese a la no existencia de un criterio unificado, se pueden identificar ciertos elementos inherentes a la cooperación internacional para el desarrollo, estos son:

- Responde al criterio de corresponsabilidad.

- Se basa sobre el criterio de solidaridad entre los pueblos, respeto y protección de los derechos humanos y en la búsqueda incesante de mejores condiciones y mayores recursos que brinden al hombre una situación de bienestar conforme a su dignidad humana.

- Comprende actuaciones tanto de actores privados como públicos.

- Debe responder a prioridades.

- Deben existir metas y estrategias comunes.

- Busca existencia de un diálogo claro y constante entre las partes que permita armonizar intereses.

- Idealmente, no debe implicar intromisión del cooperante en la política interna ni externa del país receptor.

Estas características son referentes a la cooperación internacional; no obstante, para lograr una compresión más clara, es imprescindible definir el concepto de desarrollo; igualmente, un concepto histórico y en constate mutación.

Celorio y López de Munain (2006, p. 76) consideran dos características importantes a la hora de definir este concepto. La primera de ellas es tratarlo como un concepto histórico. Cada sociedad y cada época tienen su propia formulación del desarrollo que responde a convicciones, expectativas y posibilidades que predominan en ellas.

La otra característica es que es una categoría de futuro. Cuando se establecen las prioridades del desarrollo, en última instancia se está afirmando cuál es la visión de lo que se quiere lograr en el futuro. Pensar en el desarrollo es pensar en el futuro que se quiere construir y esta 
decisión no puede ser exclusiva de unos pocos (Celorio y López de Munain, 2006, p. 77).

Por ende, teniendo en cuenta las diversas concepciones sobre el desarrollo, en el presente trabajo consideramos los lineamientos y aportes de Amartya Sen (1999) donde se incorporan gradualmente aspectos culturales, sociales y humanos que dejan de lado el corte transversal del economicismo.

De los aportes de Sen, se han desprendido numerosos trabajos de académicos, como los Todaro y Smith (2005, p. 128), quienes señalan respecto del concepto de desarrollo:

\section{se debe concebir el desarrollo como un proceso multidimensional compuesto por grandes transformaciones de las estructuras sociales, de las actitudes de la gente y de las instituciones nacionales, así como por la aceleración del crecimiento económico, la reducción de la desigualdad y la erradicación de la pobreza absoluta.}

Estos autores proponen tres valores centrales en el desarrollo: sustento vital, capacidad de satisfacer las necesidades básicas, autoestima, ser persona, libertad y no servidumbre, así como poder elegir. Este marco general permitió entender el desarrollo como mejoramiento del nivel y la calidad de vida y centrar la atención en los problemas más apremiantes en las sociedades actuales, como son la pobreza, la desigualdad, el desempleo y, en general, la falta de capacidades (Alean, 2006).

Asimismo, la propuesta de José Antonio Sanahuja (2001) goza de aceptación en el orden académico en cuanto está en línea con la conceptualización elaborada por la Organización para la Cooperación y Desarrollo Económico (OCDE) y el Programa de las Naciones Unidas para Desarrollo.

En este sentido, la cooperación internacional para el desarrollo comprende el conjunto de actuaciones, realizadas por actores públicos y privados, entre países de diferente nivel de renta, para promover el progreso económico y social de los países del Sur, de modo que sea más equilibrado en relación con el Norte y resulte sostenible. Esta dinámica garantizaría una cooperación internacional más estable, pacífica y segura para todos los habitantes del planeta (Jiménez y Rosa, 2006, p. 13).

En síntesis, se podría señalar que la evolución del concepto de cooperación internacional hacia el concepto de cooperación internacional para el desarrollo ha estado permeada por la necesidad de optimizar y maximizar los recursos (llámense financieros, técnicos, etc.) destinados por los países del Norte, tradicionalmente cooperantes, hacia los países del Sur en pro de que solucionen problemas comunes y de interés general que redunden en calidad de vida para sus pobladores (tabla 1 ).

Tabla 1. Características principales de la cooperación internacional para el desarrollo

\begin{tabular}{|c|c|c|c|c|}
\hline Origen/tipo & $\begin{array}{l}\text { Tipos de cooperación } \\
\text { y actores implicados }\end{array}$ & $\begin{array}{l}\text { Características de } \\
\text { los fondos }\end{array}$ & $\begin{array}{c}\text { Nivel de } \\
\text { concesionalidad }\end{array}$ & $\begin{array}{l}\text { Naturaleza de la } \\
\text { cooperación }\end{array}$ \\
\hline $\begin{array}{l}\text { Pública: } \\
\text { administraciones } \\
\text { nacionales, regionales } \\
\text { y locales de países } \\
\text { donantes. Privada: } \\
\text { recursos propios de } \\
\text { particulares, empresas } \\
\text { o asociaciones, etc. }\end{array}$ & $\begin{array}{l}\text { Multilateral: agencias, } \\
\text { instituciones u } \\
\text { organizaciones } \\
\text { gubernamentales } \\
\text { autónomas. Bilateral: } \\
\text { administraciones } \\
\text { públicas u } \\
\text { urganizaciones de } \\
\text { desarrollo sin carácter } \\
\text { oficial. Descentralizada: } \\
\text { administraciones } \\
\text { regionales y } \\
\text { locales públicas. } \\
\text { No gubernamental: } \\
\text { organizaciones no } \\
\text { gubernamentales de } \\
\text { desarrollo. Empresarial: } \\
\text { empresas que brindan } \\
\text { asistencia técnica } \\
\text { y transferencia de } \\
\text { tecnología. }\end{array}$ & $\begin{array}{l}\text { Reembolsable, la } \\
\text { cooperación debe ser } \\
\text { devuelta en forma de } \\
\text { dinero o en especie. } \\
\text { No reembolsable, la } \\
\text { cooperación se hace a } \\
\text { fondo perdido. }\end{array}$ & $\begin{array}{l}\text { Ayuda ligada. } \\
\text { Condiciona al receptor } \\
\text { a la compra exclusiva } \\
\text { de bienes y servicios } \\
\text { del país donante. } \\
\text { Ayuda no ligada. No } \\
\text { condiciona al receptor } \\
\text { a la compra exclusiva } \\
\text { de bienes y servicios } \\
\text { del país donante. }\end{array}$ & $\begin{array}{l}\text { Financiera: } \\
\text { transferencia real de } \\
\text { los fondos al receptor. } \\
\text { No financiera: } \\
\text { transferencia de } \\
\text { conocimientos, } \\
\text { tecnología, } \\
\text { materiales, } \\
\text { intercambios } \\
\text { culturales, deportivos, } \\
\text { etc. }\end{array}$ \\
\hline
\end{tabular}


Ahora bien, la OCDE, de la mano de las Organización de las Naciones Unidas, confecciona cada tres años el listado de aquellos países que deben ser prioritarios para recibir la cooperación internacional para el desarrollo, materializada en la ayuda oficial para el desarrollo. Dicho listado se elabora de acuerdo con el producto interno bruto (PIB) per capita de cada Estado (tabla 2).

\begin{tabular}{|c|c|c|c|}
\hline $\begin{array}{l}\text { Países menos } \\
\text { desarrollados }\end{array}$ & $\begin{array}{l}\text { Paises renta baja (< } \\
\$ 1005 / h a b \text { en } 2010)\end{array}$ & $\begin{array}{l}\text { Países y territorios de renta } \\
\text { media baja (1005-\$3975/ } \\
\text { bab en 2010) }\end{array}$ & $\begin{array}{l}\text { Países y territorios de renta } \\
\text { media alta (3976-\$12 275/ bab } \\
\text { en 2010) }\end{array}$ \\
\hline Afganistán & Corea del Norte & Armenia & Albania \\
\hline Angola & Kenia & Belice & Anguila \\
\hline Bangladés & Kuirguistán & Bolivia & Antigua y Barbuda \\
\hline Benín & Sudán del Sur & Cabo Verde & Argelia \\
\hline Burkina Faso & Tayikistán & Camerún & Argentina \\
\hline Burundi & Zimbabue & Congo & Azerbaiyán \\
\hline Bután & & Costa de Marfil & Bielorrusia \\
\hline Camboya & & Egipto & Bosnia y Herzegovina \\
\hline Chad & & El Salvador & Botsuana \\
\hline Comores & & Fiyi & Brasil \\
\hline Congo & & Filipinas & Chile \\
\hline Eritrea & & Georgia & China \\
\hline Etiopía & & Ghana & Colombia \\
\hline Gambia & & Guatemala & Costa Rica \\
\hline Guinea & & Guayana & Cuba \\
\hline Guinea Ecuatorial & & Honduras & Dominica \\
\hline Guinea-Bisáu & & India & República Dominicana \\
\hline Haití & & Indonesia & Ecuador \\
\hline Islas Salomón & & Irak & Gabón \\
\hline Kiribati & & Islas Marshall & Granada \\
\hline Laos & & Kosovo & Irán \\
\hline
\end{tabular}




\begin{tabular}{|c|c|c|}
\hline Lesotho & Marruecos & Islas Cook \\
\hline Liberia & Micronesia & Jamaica \\
\hline Madagascar & Moldavia & Jordania \\
\hline Malaui & Mongolia & Kazajistán \\
\hline Mali & Nicaragua & Líbano \\
\hline Mauritania & Nigeria & Libia \\
\hline Mozambique & Pakistán & $\begin{array}{l}\text { Macedonia (Antigua República } \\
\text { Yugoslava de Macedonia) }\end{array}$ \\
\hline Myanmar/Birmania & Territorios Palestinos & Malasia \\
\hline Nepal & Papúa Nueva Guinea & Maldivas \\
\hline Níger & Paraguay & Mauricio \\
\hline República Centroafricana & Siria & México \\
\hline Ruanda & Sri Lanka & Montenegro \\
\hline Samoa & Suazilandia & Monserrat \\
\hline Senegal & Tokelau & Namibia \\
\hline Sierra Leona & Tonga & Nauru \\
\hline Somalia & Turkmenistán & Niue \\
\hline Santo Tomé y Príncipe & Ucrania & Palau \\
\hline Sudán & Uzbekistán & Panamá \\
\hline Tanzania & Vietnam & Perú \\
\hline Timor Oriental & & San Vicente y las Ganadinas \\
\hline Togo & & Santa Helena \\
\hline Tuvalu & & Santa Lucía \\
\hline Uganda & & Serbia \\
\hline Vanuatu & & Seychelles \\
\hline Yemen & & San Cristóbal y Nieves \\
\hline Yibuti & & Sudáfrica \\
\hline Zambia & & Surinam \\
\hline
\end{tabular}




\begin{tabular}{|l|l|l|l|}
\hline & & & Tailandia \\
\hline & & & Túnez \\
\hline & & & Turquía \\
\hline & & & Uruguay \\
\hline
\end{tabular}

Fuente: OCDE (2013)

Las clasificaciones elaboradas por la OCDE y el Banco Mundial han permitido, como bien se señaló, optimizar la ayuda oficial al desarrollo de acuerdo con la condición que tiene cada Estado beneficiario. Esta clasificación es importante, debido a que hoy en día la cooperación internacional es más escasa, de ahí que la única ayuda que no exige retorno o pago de la deuda sea exclusivamente la cooperación para la ayuda humanitaria.
Sobre tipología de cooperación internacional existe diversa bibliografía y categorización; sin embargo, es importante destacar de forma precisa los tipos de $\mathrm{coo}^{-}$ peración internacional para el desarrollo más recurrentes, como la cooperación técnica y científica, técnica entre países en desarrollo, financiero-económica y educativo-cultural (becas y pasantías) (tabla 3).

Tabla 3. Tipos de cooperación internacional para el desarrollo

\begin{tabular}{|c|c|c|c|}
\hline Técnica & $\begin{array}{l}\text { Técnica entre países en } \\
\text { desarrollo }\end{array}$ & Financiero-económica & Educativo-cultural \\
\hline $\begin{array}{l}\text { Es una de las primeras } \\
\text { modalidades de cooperación } \\
\text { internacional, articuladora } \\
\text { del tradicional esquema } \\
\text { Norte-Sur. Se destina hacia } \\
\text { países en desarrollo por } \\
\text { medio de transferencias de } \\
\text { tecnologías, conocimientos, } \\
\text { experiencias y habilidades. } \\
\text { Se destacan: formación de } \\
\text { recursos humanos, cursos } \\
\text { cortos de capacitación, } \\
\text { asesorías, desarrollo de } \\
\text { proyectos piloto, envío de } \\
\text { expertos, intercambio de } \\
\text { experiencias, estancias y } \\
\text { pasantías e investigaciones } \\
\text { conjuntas. }\end{array}$ & $\begin{array}{l}\text { Surge como respuesta a "el } \\
\text { desaliento" de la cooperación } \\
\text { tradicional". Se conoce } \\
\text { también como cooperación } \\
\text { horizontal o Sur-Sur. Este } \\
\text { tipo de cooperación se } \\
\text { realiza entre países de similar } \\
\text { o menor nivel de desarrollo } \\
\text { económico. La forma de } \\
\text { funcionamiento consiste en } \\
\text { que un país solicita asistencia } \\
\text { y ofrece al mismo tiempo } \\
\text { proyectos en las capacidades } \\
\text { donde es más competitivo. }\end{array}$ & $\begin{array}{l}\text { Sucede cuando se otorgan } \\
\text { créditos, especialmente } \\
\text { blandos, para apoyar la } \\
\text { realización de proyectos de } \\
\text { larga duración, dirigidos } \\
\text { hacia la consecución del } \\
\text { desarrollo del país receptor. } \\
\text { Las fuentes más usuales } \\
\text { dentro de este tipo de } \\
\text { cooperación internacional } \\
\text { son los organismos } \\
\text { financieros multilaterales } \\
\text { (Banco Mundial, } \\
\text { Banco Interamericano } \\
\text { de desarrollo) y países } \\
\text { desarrollados, como Japón, } \\
\text { Alemania, los Estados } \\
\text { Unidos, Francia, España y } \\
\text { Gran Bretaña. }\end{array}$ & $\begin{array}{l}\text { Conocimientos educativos y } \\
\text { culturales que intercambian } \\
\text { los diferentes países y } \\
\text { organismos internacionales, } \\
\text { a través de cursos y actos } \\
\text { internacionales sobre } \\
\text { materias específicas. } \\
\text { Posgrados, congresos, } \\
\text { conferencias y demás actos } \\
\text { internacionales. }\end{array}$ \\
\hline
\end{tabular}

Panorama I
Fuente: Modificado de Agencia de Cooperación e Inversión de Medellín y el Área Metropolitana (2007)

\section{ORIGEN YEVOLUCIÓN DE LA COOPERACIÓN INTERNACIONAL}

Comprender el origen y la evolución de la cooperación internacional para el desarrollo implica entrelazar dos dimensiones. La primera de ellas se refiere a la dimensión histórica, es decir, a una serie de sucesos históricos que establecieron un contexto propicio para el surgimiento de la cooperación internacional para el desarrollo. La segunda dimensión se refiere a los avances y desarrollos teóricos, enfocados en teorías económicas desarrollistas y de dependencia (Calabuig y María, 2010). La confluencia de ambas dimensiones ha permitido el llamado sistema de cooperación internacional para el desarrollo.

El panorama desolador de destrucción y miseria derivado de la Segunda Guerra Mundial (1939-1945) forjó las condiciones que hicieron posible la aparición 
y el nacimiento de una conciencia sobre la necesidad y la importancia de la cooperación internacional como herramienta fundamental para mantener la paz y la resquebrajada seguridad internacional tan vulnerada en los años de guerra.

Las políticas de ayuda externa y la cooperación internacional para el desarrollo han sido uno de los elementos constitutivos del sistema internacional de posguerra, e incluso su rasgo histórico singular. Antes de 1945 las políticas de ayuda no existían como tales. Su evolución desde ese año responde, en gran medida, a las transformaciones que ha experimentado dicho sistema (Sanahuja, 2001).

De igual forma, en su evolución, la bibliografía sobre cooperación internacional reconoce tres momentos o hechos históricos que la han marcado, a saber: la reconstrucción de Europa en el conflicto bipolar, la descolonización de África y la globalización e integración de la economía mundial. Dichos sucesos son claves para describir el surgimiento y la evolución de la cooperación internacional hacia la cooperación internacional para el desarrollo.

\section{LOS PLANES DE RECONSTRUCCIÓN DE EUROPA EN EL CONFLICTO BIPOLAR}

La estrategia adoptada por la comunidad internacional para la reconstrucción del lacerado continente europeo y retomar el rumbo del desarrollo y bienestar fue mediante la promoción de la naciente ayuda internacional como un instrumento vector de la diplomacia y las relaciones internacionales.

Las operaciones militares de la Segunda Guerra Mundial afectaron un área mucho más amplia que la que había sido escenario de la Primera Guerra Mundial (1914-1918), en su mayor parte europea. En Europa y en la cuenca del mediterráneo, solo Suecia, Suiza, España, Portugal e Irlanda pudieron mantenerse neutrales (Procacci, 1999, p. 303).

Inmediatamente finalizada la guerra, los países europeos se vieron sumidos en una situación precaria y desoladora, caracterizada por un proceso de reconstrucción entorpecido y lento, matizado por las siguientes razones:
1) La desconfianza de los inversores, los conflictos sociales que obstaculizaban la recuperación económica y, sobre todo, la drástica escasez de dólares: el dollar gap que a finales de 1946 se elevaba para los países de Europa Occidental a unos US\$7000 millones (Mammarella, 1996, p. 84).

2) La crisis alimentaria que amenazaba peligrosamente la recuperación económica de la posguerra, el hambre, la desnutrición y las enfermedades de miles y miles de europeos damnificados estaban creando una situación límite.

A pesar que el Gobierno de los Estados Unidos concedió a Europa Occidental desde el final de la guerra una ayuda oficial de más de US $\$ 4500$ millones, más otros US\$6800 millones en forma de crédito, la situación económica de esta región parecía no mejorar significativamente. Es el caso de los índices de producción agrícola e industrial, los cuales descendieron en todos los países europeos.

Todo ello hizo que se comenzara a planificar una gran operación de ayuda económica internacional (Mammarella, 1996, p. 423). Tal operación se materializó en el Plan Marshall, denominado oficialmente European Recovery Program, el cual inicialmente se ofreció a todas las naciones europeas, incluida la entonces Unión Soviética, en ciertas condiciones. Sin embargo, solo 16 países europeos recibieron los beneficios del plan, de los cuales se excluyeron España, Finlandia y los Estados que, después de terminada la guerra, quedaron en la órbita de influencia soviética (tabla 4).

Tabla 4. Distribución de la ayuda oficial proveniente del Plan Marshall

\begin{tabular}{|l|r|r|} 
País & $\begin{array}{l}\text { Ayuda oficial } \\
\text { en millones de } \\
\text { US\$ }\end{array}$ & $\begin{array}{l}\text { Población } \\
\text { beneficiada en } \\
\text { 1951 }\end{array}$ \\
\hline $\begin{array}{l}\text { Alemania } \\
\text { Occidental }\end{array}$ & 1448 & 68375 \\
\hline Austria & 488 & 6935 \\
\hline Bélgica & 777 & 296 \\
\hline Dinamarca & 385 & 4271 \\
\hline
\end{tabular}




\begin{tabular}{|c|c|c|c|}
\hline \multirow{2}{*}{$\begin{array}{r}\text { Lisbeth } \\
\text { Katherine }\end{array}$} & País & $\begin{array}{l}\text { Ayuda oficial } \\
\text { en millones de } \\
\text { US\$ }\end{array}$ & $\begin{array}{l}\text { Población } \\
\text { beneficiada en } \\
1951\end{array}$ \\
\hline & Francia & 2296 & 42518 \\
\hline Duarte Herrera I & Grecia & 366 & 7566 \\
\hline González & Irlanda & 133 & 2963 \\
\hline Parias I & Islandia & 43 & 143 \\
\hline & Italia & 1204 & 47105 \\
\hline & Noruega & 372 & 3265 \\
\hline & Países Bajos & 1128 & 10121 \\
\hline & Portugal & 70 & 8443 \\
\hline & Reino Unido & 3297 & 50127 \\
\hline & Suecia & 347 & 7014 \\
\hline & Suiza & 250 & 4694 \\
\hline & Turquía & 137 & 21122 \\
\hline & Total & US\$12 741 & 284958 \\
\hline
\end{tabular}

Fuente: Modificado de Contreras (2013).

La vigencia del Plan Marshall comprendió el periodo 1948-1952, en el cual se destinaron alrededor de US $\$ 13000$ millones de ayuda, distribuidos principalmente bajo el criterio de renta per capita, que terminó favoreciendo de manera indirecta a los países aliados.

Se puede considerar el Plan Marshall como un proceso embrionario de la cooperación internacional moderna, cuyo propósito fue aportar a la reconstrucción económica de Europa. Claro está, el Plan fue un instrumento estadounidense direccionado para superar la crisis económica de la posguerra que no solo aseguraba la recuperación europea, sino también de los mercados. Ahora bien, tampoco se puede desconocer que el Plan Marshall tenía por objetivo fortalecer el bloque capitalista $u$ occidental, teniendo en cuenta que el telón de fondo, en los años de posguerra, fue la lucha ideológico-política entre los Estados Unidos y la entonces Unión Soviética, conocida como guerra fría. En este sentido, Griffin $124 \mid$ (1991) señala:
Los programas de ayuda exterior no fueron otra cosa que un subproducto de la guerra fría: la confrontación ideológica entre el este y el oeste habría determinado el destino real de los flujos de ayuda, de tal manera que quedaban asignados de acuerdo con criterios geoestratégicos, buscando en último término el establecimiento de "zonas seguras" (citado en Calabuig, 2010, p. 14).

Lo anterior indica que la cooperación internacional entregada durante los años de posguerra no solo puede ser catalogada como ayuda humanitaria haciendo alusión a los efectos de la guerra, sino también como un instrumento diplomático de derecho útil para mantener aliados en la configuración bipolar de fuerzas y sostener el modelo económico imperante.

\section{LOS PROCESOS DE DESCOLONIZACIÓN EN LOS AÑOS DE POSGUERRA}

Antes del inicio de la Primera Guerra Mundial, el mundo dependía o giraba en torno a un reducido grupo de potencias coloniales europeas, conocido como el sistema europeo. Sin embargo, tras el final de esta conflagración - que trajo consigo la desaparición de imperios coloniales, como el otomano y el austrohúngarocomenzaron a debilitarse las bases del colonialismo e iniciaron los procesos de descolonización, mayoritariamente en Asia (es el caso de la India). No obstante, fue hasta el final de la Segunda Guerra Mundial cuando este proceso se potenció y generalizó en los territorios dominados en África, Asia, Oceanía y el Caribe.

Así es como, en pocos años, surge un gran abanico de nuevos Estados en condiciones precarias de subsistencia, con economías de bajo nivel de desarrollo, renta per capita baja — economías dedicadas a la producción agrícola-, industria incipiente, sistemas educativos de muy poca cobertura, alto nivel de analfabetismo, elevadas tasas de mortalidad infantil y sistemas de salud precarios incapaces de evitar la propagación de enfermedades. Por consiguiente, estaban naciendo sociedades con incapacidad de responder a la problemática interna y generar desarrollo en el interior de su territorio.

Frente a este panorama impulsado por una especie de deuda histórica y moral que en términos más realistas buscaba no perder completamente la influencia sobre las excolonias implementado así el llamado 
neocolonialismo ${ }^{1}$, las antiguas potencias coloniales fueron las primeras en ensayar la cooperación internacional dirigida al denominado Tercer Mundo, que tenía como objetivo promover su desarrollo con la transferencia de ayuda oficial para el desarrollo materializada en tecnología, financiamiento, asesoría técnica, implementación de instituciones y modelos occidentales de democracia y buenas prácticas.

Hasta este punto se pueden inferir dos características en la cooperación internacional para el desarrollo. La primera de ellas se encaminó hacia la recuperación de sociedades que se encontraban en un punto alto de desarrollo económico y tecnológico, pero devastadas por la Segunda Guerra Mundial, y la segunda a potenciar sociedades que durante años se encontraron sumidas en una directa dependencia política y económica respecto de las metrópolis coloniales, lo que les impedía la autodeterminación y autonomía para su desarrollo.

De igual forma, se puede deducir que las ideas bajo las cuales descansaba y se fundamentaba la cooperación internacional para el desarrollo, en la década de 1950, era la premisa del crecimiento económico. En este sentido, se consideraba como una vía para promover y ayudar al desarrollo de ciertos países con la transferencia de capital. Es decir, el objetivo era el crecimiento económico, aumentar el volumen de bienes y servicios producidos, para lo cual los componentes básicos del desarrollo eran el progreso tecnológico, la industrialización y la urbanización, los cuales eran capaces de generar un aumento de la productividad, los ingresos y el bienestar (Celorio y López de Munain, 2006).

\section{LAS DINÁMICAS DE LA GLOBALIZACIÓN Y LA PAULATINA INTEGRACIÓN DE LA ECONOMÍA MUNDIAL}

Si bien algunos teóricos como Inmanuel Wallerstein (Patiño y Suárez, 2003) señalan que la globalización ha existido como mínimo desde cuatrocientos años atrás, esta globalización se refiere a los profundos cambios en esferas tanto económicas como políticas que se han presentado en el mundo entero desde el último cuarto de siglo de la centuria pasada, caracterizado por

1 Se entiende como neocolonialismo al control indirecto que ejercen las antiguas potencias coloniales sobre sus antiguas colonias o, en sentido amplio, los Estados hegemónicos sobre los subdesarrollados. Estos países no disfrutan de una independencia plena, sino que están sometidos a los dictados culturales, políticos, lingüísticos y, especialmente, económicos, de otro. la tendencia a la eliminación de las barreras fronterizas con la consecuente profundización de los procesos de integración regional y el cambio de relaciones globales con los Estados nacionales así como con los territorios locales.

La cooperación internacional no ha sido ajena a los diversos cambios generados por los procesos de globalización, puesto que le ha impreso dimensiones y nuevos actores, además de los Estados, a saber: organismos internacionales, entes privados y públicos, transnacionales, sociedad civil nacional e internacional organizada, organizaciones no gubernamentales, bancos regionales, entre otros. Debido a la heterogeneidad de estos actores, la cooperación internacional para el desarrollo ha empezado a atravesar una diversidad de dimensiones, como las sociales, culturales, económico-financieras y políticas, sin que sea una condición imprescindible la cercanía geográfica.

Ahora bien, durante la década de 1970, la ayuda oficial al desarrollo, entendida como "el flujo de mayor concesionalidad dentro de las corrientes de financiamiento externo" (Pérez, 2011, p. 1), es decir, dicha ayuda lleva al menos un porcentaje de donación, se fue incrementando paulatinamente, de suerte que en 1980 fue tres veces superior a la desembolsada en 1970, lo que indica que la pluralidad de actores internacionales favoreció la entrada de nuevos cooperantes (tabla 5).

Tabla 5. Ayuda oficial para el desarrollo desembolsada durante la década de 1970

\begin{tabular}{|r|r|} 
Año & Total AOD \\
\hline 1970 & 5420 \\
\hline 1971 & 6033 \\
\hline 1972 & 6246 \\
\hline 1973 & 6674 \\
\hline 1974 & 7784 \\
\hline 1975 & 9211 \\
\hline 1976 & 8809 \\
\hline 1977 & 9297 \\
\hline
\end{tabular}




\begin{tabular}{|c|c|c|}
\hline & Año & Total AOD* \\
\hline & 1978 & 12265 \\
\hline & 1979 & 15334 \\
\hline Duarte Herrera I & 1980 & 17019 \\
\hline
\end{tabular}

* Ayuda oficial para el desarrollo desembolsada en millones de US\$, precios corrientes.

Fuente: Modificado de OCDE (2013)

De igual manera, la globalización y las progresivas integraciones político-económicas han generado que ciertas problemáticas que en tiempos anteriores eran exclusivas de algunos Estados tomen carácter internacional: enfermedades pandémicas, cultivo y tráfico de drogas ilícitas, migración ilegal, terrorismo, entre otros. En lo que respecta a la problemática de cultivo y tráfico de drogas ilícitas, Colombia ha sido uno de los países receptores de cooperación, en cuanto ha recibido ayuda internacional en sus zonas fronterizas, para erradicar y prevenir la propagación de esta problemática hacia los países limítrofes. Por esta razón, para el control y la erradicación de tales problemáticas la cooperación internacional se ha convertido en una herramienta y en un instrumento clave de los Estados y demás instituciones.

Las grandes disparidades en las condiciones económicas de los países persisten y han venido aumentado. Lo anterior se evidencia en el crecimiento de la deuda externa y la propagación de la pobreza. En este mundo fragmentado y desigual, no todos los países ni los grupos dentro de los países están "integrados" en los mercados globales; existen enormes segmentos de la población mundial que siguen marginados. De igual manera,

\section{Tal profundización de las desigualdades entre los países ricos y los subdesarrollados, que se evidencia con más claridad tras el fin de la guerra fría, hace de la cooperación internacional para el desarrollo una necesidad más urgente de la que ya representaba durante la vigencia del conflicto Este-Oeste (Tokatlian y Carvajal, 1995, p. 21).}

Por lo tanto, y de acuerdo con la breve construcción de la evolución de la cooperación internacional para el desarrollo, queda claro que esta nació y se empezó desarrollando bajo el credo axiomático que se refiere a que el crecimiento económico era igual a desarrollo, y con una constante estructura vertical. Es decir, esta concepción, dominada por los países donantes, no se caracterizó por la igualdad y la colaboración mutua, sino por la verticalidad manejada por el Norte que veía en este instrumento un medio para evitar los obstáculos que el Sur, en medio de su subdesarrollo, causa al proyecto modernizante.

Era una concepción de la cooperación que no tenía en cuenta las características intrínsecas, las peculiaridades, las reales y más prioritarias necesidades de los Estados receptores. Igualmente, muy poco, o en nada, durante más de cuatro décadas, contribuyó al cierre de la brecha entre Norte y Sur, brecha que durante este periodo se ahondó más. El Norte, a pesar de sus contradicciones, encarna el desarrollo y el bienestar, por lo tanto hay que intentar cambiar el Sur que es lo que verdaderamente no funciona o funciona mal (Celorio y López de Munain, 2006, p. 39).

\section{CRISIS DE LA COOPERACIÓN INTERNACIONAL PARA EL DESARROLLO}

Entre las décadas de 1980 y 1990 la cooperación internacional para el desarrollo empezó a manifestar una desaceleración y posterior crisis, generada principalmente por tres factores: en primer lugar, los pobres resultados en torno a impulsar el desarrollo de las naciones del Tercer Mundo, donde los cooperantes o donantes expresaron una "fatiga de cooperación" en relación con los pobres resultados frente a los profundos problemas. En términos de desarrollo, esta década pasará a la historia como la década perdida y la constatación, una vez más, de que la ayuda al desarrollo no había funcionado (Calabuig y María, 2010, p. 8). El segundo factor se refiere al contexto político internacional de fin del bipolarismo donde los Estados desarrollados ya no veían como una necesidad de estrategia geopolítica mantener zonas de influencia político-ideológica. El tercer factor se refiere al campo teórico; en estos años se inicia el denominado debate de los development studies, el cual tiene su origen en distintos factores: las limitaciones explicativas de las teorías, las debilidades de las políticas en cuanto a su impacto y sostenibilidad, así como los cambios en curso en los escenarios locales, nacionales y globales (Ianni, 2005).

De igual manera, teniendo en cuenta el contexto y bajo la égida del pensamiento dominante en relaciones 
internacionales (el realismo), la cooperación internacional poseía un papel marginal en un pensamiento donde rige el principio de acción propio de un sistema permeado por la desconfianza y los intereses particulares de los Estados que más tienen poder en el ámbito internacional. Lo anterior indica que le corresponde a cada Estado ser el único responsable de garantizar su supervivencia, bienestar y desarrollo mientras no existan instituciones supranacionales sólidas y, sobre todo, neutrales.

Tal pensamiento dominante en las relaciones internacionales relegaba a un segundo plano los nobles propósitos de la cooperación internacional y le otorga protagonismo, poder e influencia al Estado "cooperante", para lograr una mejor posición dentro del concierto internacional. La fatiga de la cooperación internacional para el desarrollo también coincide con la época de discusión y de surgimiento de nuevos paradigmas que pretendían darle explicación a los fenómenos internacionales, tales como el nuevo institucionalismo en las relaciones internacionales, el estructural funcionalismo, el neoliberalismo y el nuevo realismo.

De igual forma, los canales de recepción también desepeñaron un papel importante en generar dicha crisis en la cooperación internacional. La precaria institucionalidad tanto para su emisión como para su recepción originaba pérdida de recursos, destinatarios innecesarios y formulación de proyectos que respondían a necesidades poco relevantes. Finalmente, la crisis en la cual se encontró la cooperación se debió, en gran parte, a la crisis de los paradigmas presentados a finales de la década de 1980 y durante la década de 1990, entre los que se encontraban bajo un serio cuestionamiento la concepción de desarrollo. En la tabla 6, se aprecia cómo en 1991 los desembolsos por ayuda oficial para el desarrollo alcanzaron una cifra de US\$43027 millones y cómo fueron disminuyendo paulatinamente, de suerte que en 1997 se desembolsaron US\$32 508 millones, cifra menor a la de 1989, ocho años atrás.

Tabla 6. Ayuda oficial desembolsada durante 1985-1999

\section{Año Total AOD (millones de US\$)}

1985

21203

1986

25226

\begin{tabular}{|c|c|}
\hline 1987 & 28889 \\
\hline 1988 & 31958 \\
\hline 1989 & 32934 \\
\hline 1990 & 38477 \\
\hline 1991 & 43027 \\
\hline 1992 & 42819 \\
\hline 1993 & 39096 \\
\hline 1994 & 41053 \\
\hline 1995 & 40552 \\
\hline 1996 & 39211 \\
\hline 1997 & 32508 \\
\hline 1998 & 35354 \\
\hline 1999 & 37990 \\
\hline res & \\
\hline
\end{tabular}

La particularidad de la crisis, de la que hay que apreciar los bloques y también las oportunidades de orientación y desarrollo que presenta, radica en la exigencia que plantea de realizar un reajuste profundo de los modelos teóricos y estratégicos adoptados, es decir, en la puesta en discusión amplia, y en algunos casos radical, del camino recorrido en los cincuenta años de vida de la cooperación internacional para el desarrollo (Vanna, 2005, p. 79).

No obstante, después de lo que podríamos denominar etapa de revisión e introspección de la tradicional cooperación internacional para el desarrollo, finalizando el siglo XX e inicios del XXI, esta experimenta una oxigenación gracias a un nuevo paradigma de desarrollo humano y a la ampliación de la agenda y temas prioritarios: 
Katherine

Duarte Herrera I

Carlos Hernán

González

Parias I

Panorama I

pp. $117-131$ |

Volumen 81

Número 15 |
En los años noventa se asiste a la conformación de un nuevo paradigma en las teorías del desarrollo, el desarrollo humano, que se irá difundiendo a través de los distintos informes del Programa de Naciones Unidas para el Desarrollo y con la celebración de distintas conferencias internacionales auspiciadas por las Naciones Unidas. Asimismo, se va abriendo camino en la agenda del desarrollo la preocupación por la participación de los pobres, con la introducción de las evaluaciones participativas de la pobreza (Participatory Poverty Assessments en su terminología inglesa) popularizadas por el Banco Mundial. Los últimos años de los noventa y los primeros del siglo XXI arrancan con un importante consenso mundial sobre la importancia de la lucha contra la pobreza. El documento que mejor recoge este acuerdo son los Objetivos de Desarrollo del Milenio definidos en el año 2000 (Calabuig y María, 2010, p. 8).

\section{CAMBIOS EN LA CONCEPCIÓN DE LA COOPERACIÓN INTERNACIONAL PARA EL DESARROLLO}

Si bien en la actualidad no existe un modelo claro de cooperación internacional para el desarrollo, últimamente se está apostando por un esquema más horizontal, más participativo, menos tecnocrático y menos economicista donde la progresiva aceptación del enfoque del desarrollo humano ha tomado gran importancia para la reconfiguración de lo que se conoce como cooperación internacional para el desarrollo. En este sentido, es importante remitirse al concepto de desarrollo humano trabajado por el Programa de las Naciones Unidas para el Desarrollo (PNUD):

Representa un proceso a la vez que un fin. En todos los niveles del desarrollo las tres capacidades esenciales consisten en que la gente viva una vida larga y saludable, tenga conocimientos y acceso a recursos necesarios para un nivel de vida decente. Pero el ámbito del desarrollo humano va mucho más allá: otras esferas de opciones que la gente considera en alta medida incluyen la participación, la seguridad, la sostenibilidad, las garantías de los derechos humanos, todas necesarias para gozar de respeto por sí mismo, potenciación y una sensación de pertenecer a una comunidad. En definitiva, el desarrollo humano es el desarrollo de la gente, para la gente y por la gente (2001, p.17).
De igual forma, el surgimiento de nuevos actores en el medio, tales como las organizaciones no gubernamentales, las organizaciones no gubernamentales para el desarrollo (ONG y ONGD) y los movimientos sociales, han abierto un nuevo debate sobre los objetivos de la cooperación para el desarrollo. Lo cual ha contribuido a que desde finales del siglo pasado y durante la década de 2010 se realice una profunda reorientación y revisión del concepto de desarrollo, haciendo así una dura crítica al modelo basado en la expoliación ambiental, en el consumo desmedido, en el derroche energético, proponiendo alternativas de desarrollo más humano, más participativo y, por lo tanto, incentivando a reestructurar la cooperación, sus instituciones y las maneras de gestionar la equidad, como también la formulación y evaluación de los proyectos (Celorio y López de Munain, 2006, p. 77).

El 2000 marcó para la cooperación internacional para el desarrollo un año de redefinición de objetivos y de agenda internacional, lo cual significó la definición de nuevas tendencias hacia donde intensificar y buscar el desarrollo de los países receptores. Durante este año, la Asamblea General de las Naciones Unidas aprobó por unanimidad las metas del milenio como compromiso de los países para reducir los mayores factores de desequilibrio en el mundo y alcanzar mayor desarrollo (tabla 7).

Tabla 7. Ayuda oficial desembolsada durante la década de 2010

\begin{tabular}{lc}
\multicolumn{1}{c}{ Año } & Total AOD \\
\hline 2000 & 36220.41 \\
\hline 2001 & 35336.26 \\
\hline 2002 & 41012.36 \\
\hline 2003 & 50103.62 \\
\hline 2004 & 54750.22 \\
\hline 2005 & 83059.16 \\
\hline 2006 & 77520.55 \\
\hline 2007 & 73680.16 \\
\hline 2008 & 87083.49 \\
\hline
\end{tabular}


* Ayuda oficial para el desarrollo desembolsada en US\$, precios corrientes. Fuente: Modificado de OCDE (2012).

Tal declaración ha supuesto una novedad en la toma de conciencia por parte de la comunidad internacional de la universalidad del desarrollo, hasta tal punto que desde su promulgación se han convertido en referente indispensable para el desarrollo social y en la carta de navegación tanto para los flujos de cooperación internacional como para ciertos cooperantes estatales, bilaterales, que han ajustado su política de cooperación en pro del logro de tales objetivos, cuyo año de meta se trazó para 2015.

De manera breve, los Objetivos de Desarrollo del Milenio (Organización de las Naciones Unidas, 2012), son:

1) Erradicar la pobreza extrema y el hambre. Reducir a la mitad el porcentaje de personas cuyos ingresos sean inferiores a un dólar por día y reducir a la mitad el porcentaje de personas que padecen hambre.

2) Lograr la enseñanza primaria universal. Velar por que todos los niños y las niñas puedan terminar un ciclo completo de enseñanza primaria.

3) Promover la igualdad entre los géneros y la autonomía de la mujer. Eliminar las desigualdades entre los géneros en la enseñanza primaria y secundaria, preferiblemente para 2005, y en todos los niveles de la enseñanza para 2015.

4) Reducir la mortalidad infantil. Reducir en dos terceras partes la tasa de mortalidad de los niños menores de 5 años.

5) Mejorar la salud materna. Reducir la tasa de mortalidad materna en tres cuartas partes.

6) Combatir el VIH/sida, el paludismo y otras enfermedades. Detener y comenzar a reducir la propagación del VIH/sida, y otras enfermedades graves.
7) Garantizar la sostenibilidad del medio ambiente, incorporar los principios de desarrollo sostenible en las políticas y los programas nacionales, invertir la pérdida de recursos del medio ambiente, reducir a la mitad el porcentaje de personas que carecen de acceso al agua potable, mejorar considerablemente la vida de por lo menos 100 millones de habitantes de tugurios para 2020.

8) Fomentar una asociación mundial para el desarro1lo. Desarrollar aún más un sistema comercial y financiero abierto, basado en normas, previsible y no discriminatorio. Ello incluye el compromiso de lograr una buena gestión de los asuntos públicos y la reducción de la pobreza, en cada país y en el plano internacional. Atender las necesidades especiales de los países menos adelantados. Ello incluye el acceso libre de aranceles y cupos para las exportaciones de los países menos desarrollados, el programa mejorado de alivio de la deuda de los países pobres muy endeudados y la cancelación de la deuda bilateral oficial, igualmente la concesión de una asistencia oficial para el desarrollo más generosa a los países que hayan mostrado su determinación de reducir la pobreza. Atender a las necesidades especiales de los países en desarrollo sin litoral y de los pequeños Estados insulares en desarrollo. Encarar de manera general los problemas de la deuda de los países en desarrollo con medidas nacionales e internacionales para hacer la deuda sostenible a largo plazo. En cooperación con los países en desarrollo, elaborar y aplicar estrategias que proporcionen a los jóvenes un trabajo digno y productivo. En cooperación con las empresas farmacéuticas, proporcionar acceso a los medicamentos esenciales en los países en desarrollo. En colaboración con el sector privado, velar por que se puedan aprovechar los beneficios de las nuevas tecnologías, en particular, los de las tecnologías de la información y de las comunicaciones.

En síntesis, los Objetivos de Desarrollo del Milenio se han convertido en la carta de navegación en materia de cooperación internacional para el desarrollo; es decir que los Estados cooperantes han privilegiado la ayuda oficial para el desarrollo al amparo de proyectos que le apunten a superar las ocho metas de desarrollo consensuadas. Sin embargo, nos encontramos en 2015, plazo fijado para el cumplimiento de los objetivos y los desafíos que enfrenta la cooperación internacional para el desarrollo son mayores, máxime cuando los efectos y las consecuencias de la globalización han hecho mella en e

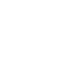


los territorios profundizan la crisis económica y humanitaria, cuyas repercusiones cada vez involucran mayor población mundial.

\section{CONCLUSIONES}

La cooperación internacional para el desarrollo es característica importante en el actual sistema internacional, se constituye como una herramienta de relacionarse no solo entre Estados, sino también entre los diferentes actores del sistema. Su surgimiento va muy de la mano del desarrollo mismo de la sociedad internacional actual y de la institucionalidad internacional. Incluso, como se demostró en el artículo, la cooperación internacional para el desarrollo ha sido sensible y ha experimentado grandes cambios y evolución a causa de sucesos y dinámicas en el interior del sistema internacional. En palabras de Uldaricio Figueroa (1989, p.539): "la cooperación internacional es uno de los elementos que ha conducido a que las relaciones internacionales pasen a un nuevo plano en la historia y marquen un hito en la concepción de una nueva sociedad internacional".

En este orden de ideas, en los cerca de sesenta y cinco años de existencia de la cooperación internacional para el desarrollo, esta ha sobrepasado las relaciones bilaterales y se ha convertido en una realidad multilateral y con múltiples actores. La cooperación internacional se presenta en la actualidad como una herramienta de suma importancia y eficiente para corregir evidentes disparidades, vacíos y falencias de procesos integracionistas en la globalizacion. La internacionalización de ciertas problemáticas ya no solo corresponde su solución al territorio o Estado que las padece, sino que se vuelven problemáticas que tracienden las fronteras nacionales y su solución, control o erradicación se convierte en responsabilidad de la comunidad internacional.

Panorama I pp. 117-131। Volumen 8 । Número 15 |

De igual manera, la cooperación internacional para el desarrollo en la actualidad se debe entender como multidimensional y dinámica. Lo primero se refiere a la necesidad de entenderla desde una perspectiva que involucra diversos temas de agenda, a causa de los procesos y cambios que ha experimentado. Por otro lado, no se debe entender como un proceso estático en el tiempo, sino como algo dinámico que debe ajustarse a las necesidades particulares de los territorios y contextos históricos específicos.
De esta manera, proximamente tanto la cooperación como el sistema de las Naciones Unidas se ven enfrentados a la necesidad de reorientar y oxigenar nuevamente las dinámicas y procesos de cooperaccion. Este nuevo reto se presenta a causa de la finalizacion del plazo establecido en la cumbre del milenio para lograr los Objetivos del Milenio para 2015. Después de un proceso de análisis, evaluación y retroalimentación de logros, deudas, obstáculos y demás experiencias surgidas, se debe establecer la naturaleza de los nuevos objetivos, las estrategias, los actores involucrados y las nuevas directrices que regirán la cooperacion internacional para el desarrollo "pos-Objetivos del Milenio", claro está si es que no siguen siendo los mismos objetivos de la agenda actual, en cuanto universalmente no se han podido alcanzar.

\section{REFERENCIAS BIBLIOGRÁFICAS}

1. Agencia de Cooperación e Inversión de Medellín y el Área Metropolitana (ACIM). (2007). Manual de cooperación internacional descentralizada. Recuperado de: http://www. acimedellin.org/Portals/0/Images/pdf_publicaciones/manual_de_cooperacion_2007.pdf

2. Alean, A. (2006, junio). El concepto de desarrollo. Recuperado de http://www. unitecnologica.edu.co/descargas/taller/ Elconceptodedesarrollo_AAlean.pdf

3. García, J. F. B., Muñoz, L. M. B., Castañeda, P. M. y Gómez, L. G. (2003). Análisis de experiencias en cooperación internacional al desarrollo de las ONG federadas de Antioquia.

4. Calabuig, C.y María, D. L. (2010). La cooperación internacional para el desarrollo. Valencia: Editorial Universitad Politécnica de Valencia.

5. Casassas, J. (2005). El mundo desde 1848 hasta nuestros días. La construcción del presente. Madrid: Ariel.

6. Celorio, G. y López de Munain, A. (2006). Diccionario de educación para el desarrollo. Bilbao: Hegoa.

7. Contreras Márquez, F. J. (2013). Sobre el Plan Marshall de reconstrucción de Europa y el plan del socialismo del siglo XXI en Venezuela. Recuperado de http://franciscojcontrerasm. blogspot.com/2013/12/sobre-el-plan-marshall-de.html

8. Figueroa, U. (1989). Manual de organismos internacionales. Santiago de Chile: Editorial Jurídica de Chile. 
9. Griffin, K. (1991). Foreign aid after the cold war. Development and Change, 22(4), 645-685.

10. Ianni, V. (2005). La sociedad civil: enfoques y modalidades de acción. Madrid: Iepala.

11. Jiménez, S. y Rosa, M. L. (2006). Desplazamiento forzado y cooperación internacional, operación prolongada de socorro y recuperación en Cartagena 2000-2005. Cartagena de Indias: Escuela Latinoamericana de Cooperación y Desarrollo.

12. Keohane, R. (2005). Interdependencia, cooperación y globalismo. Ensayos escogidos de Robert $O$. Keohane. México: CIDE.

13. Maldonado, M. (2013). Los organismos internacionales en la era global: los nuevos retos de la cooperación internacional. México: Porrúa.

14. Mammarella, G. (1996). Historia de Europa contemporánea desde 1945 hasta hoy. Barcelona: Ariel.

15. Martínez, A. (1995). Visión global de la cooperación para el desarrollo. La experiencia internacional y el caso español. Alcalá: Icaria.

16. Murguialday, C., Pérez De Armiño, K. y Eizagirre, M. (2000). Diccionario de acción bumanitaria y cooperación al desarrollo. Bilbao/ Barcelona: Icaria Editorial, Hegoa, Facultad de Ciencias Económicas, Universidad del País Vasco.

17. OCDE (2013). International development statistics (IDS) online databases. Recuperado de http://www.oecd.org/dac/stats/idsonline.htm

18. Organización de las Naciones Unidas (2012). Objetivos de Desarrollo del Milenio. Recuperado de http://www.un.org/es/millenniumgoals/

19. Patiño, C. A. y Suárez,J. O. (2003). Identidades, poderes, conflictos y metáforas. Medellín: Pontificia Universidad Bolivariana.

20. Pérez, V. (2011) La ayuda oficial para el desarrollo: tendencias y contradicciones. La Habana: Universidad de la Habana. Recuperado de: http://www.uh.cu/centros/ciei/biblioteca/publicaciones/2011/05-LaAOD.pdf

21. Procacci, G. (1999). Historia del siglo XX. Barcelona: Memoria crítica.

22. Programa de Naciones Unidas para el Desarrollo (2001). Informe sobre desarrollo bumano 2001.
23. Sanahuja Perales, J. A. (2001). Cooperación al desarrollo y globalización: entre la beneficencia pública internacional y el estado del bienestar mundial. Recuperado de http://www. fongdcam.org/manuales/educaciondesarrollo/ datos/docs/A_docs/5_2_Beneficencia $\% 20 \circ \% 20$ welfare.pdf

24. Red Argentina para la Cooperación Internacional (2010). Manual de Cooperación Internacional, una herramienta de fortalecimiento para las organizaciones de la sociedad civil (OSC). Recuperado de http://www.raci.org.ar/recursos-para-ong/ manual-de-cooperacion-internacional/ manual-de-cooperacion-internacional-una-herramienta-de-fortalecimiento-para-las-organizaciones-de-la-sociedad-civil-osc/

25. Sen, A. (1999). Development as freedom. Oxford University Press.

26. Todaro, M. y Smith, S. (2005). Economic development. Nueva York: Wesly.

27. Tokatlian, J. G. y Carvajal, L. (1995). Tendencias de la cooperación internacional en la posguerra fría. Colombia Internacional, 25, 20.

28. Vanna, I. (2005). La sociedad civil y cooperación internacional al desarrollo. Enfoques teóricos y modalidades de acción. Madrid: Iepala. 